\title{
Results of a controlled clinical trial of glutathione in cases of hepatic cirrhosis
}

\author{
G. C. COOK AND SHEILA SHERLOCK \\ From the Department of Medicine, The Royal Free Hospital, London
}

EDITORIAL SYNOPSIS Oral glutathione was not of any demonstrable benefit to patients with hepatic cirrhosis. It was carefully studied because it is known to assist detoxication processes of exogenous substances but its role with endogenous metabolites has received little attention.

Glutathione is a tripeptide consisting of $\gamma$-glutamyl cysteinyl-glycine and occurs in all living cells. It possesses a thiol group and participates in oxidation reduction reactions in animal metabolism. It is also an important enzyme co-factor. It was first synthesized in 1935 by Harington and Mead, and its chemistry and biochemical properties have been reviewed by Wieland (1954), Jocelyn (1958), and Isherwood (1959).

Althoughly widely distributed in animal tissues, glutathione is present in large concentrations in the liver (Waelsch, 1952), and hepatic synthesis is particularly high (Waelsch and Rittenberg, 1941; Bloch and Anker, 1947; Bloch, 1949; Johnston and Bloch, 1951; Douglas and Mortensen, 1956). Glutathione is important in detoxication (Javitt, 1961). Many organic compounds are excreted in the urine conjugated with cysteine by thio-ether linkage, as mercapturic acids, which often originate from glutathione conjugation (Barnes and James, 1957; Bray and Franklin, 1957; Binet and Wellers, 1951). Booth, Boyland, and Sims (1960) showed that naphthalene, which is excreted as a mercapturic acid, forms a glutathione conjugate when incubated with rat liver homogenate. Thiol compounds, including glutathione, protect rats against the acute liver injury induced by carbon tetrachloride and chloroform (Brunschwig, Johnson, and Nichols, 1945). Bromsulphalein (BSP) is conjugated with glutathione in the liver (Javitt, Wheeler, Baker, Ramos, and Bradley, 1960). There seems to be no doubt regarding the importance of glutathione in the detoxication of exogenous substances but its role in detoxicating endogenous metabolites has received less attention.

Since the normal intact rat liver produces glutathione rapidly in large amounts (Douglas and Mortensen, 1956) a diminished production of this substance would be expected in hepato-cellular disease. Lindan and Work (1953) showed a reduction in glutathione in the livers of rats fed a necrogenic diet. Regeneration of liver is associated with a rise in its glutathione content (Christensen, Rothwell, Sears, and Streicher, 1948). In man low levels of blood glutathione have been found in chronic liver disease (De Groote and Vandenbroucke, 1956), the level corresponding approximately to the extent of hepatic dysfunction; the glutathione level rose during recovery. In a study of 103 children with various types of liver disease the level of blood glutathione was usually low during the illness but rose during recovery (Helbeig, 1954). It therefore seemed reasonable to investigate the effect of glutathione on patients with liver disease. Studies involving the administration of sulphur containing amino-acids (methionine and cysteine) to patients with infectious hepatitis (Beattie and Marshall, 1944; Peters, Thompson, King, Williams, and Nicol, 1944) have suggested that the length of the clinical course may be shortened and the rate of fall of serum bilirubin hastened by these substances. Since no form of therapy has been established as beneficial to the liver in established cirrhosis, it was decided to assess the value of glutathione in patients with this disease.

\section{PATIENTS STUDIED AND ORGANIZATION} OF THE CLINICAL TRIAL

The clinical trial was arranged in two separate parts. In the first part, 20 cirrhotic patients were divided by a double blind technique into two equal groups (Table I). The 10 'control' patients received two placebo tablets three times daily for 28 days. There were five males and five females in this group, and the mean age was 44 years (16-58 years). The diagnoses, established in all cases by percutaneous liver biopsy, were: active 'juvenile' cirrhosis (Read, Sherlock, and Harrison, 1963) (active chronic hepatitis) (3), post-necrotic (4), primary biliary 
TABLE I

SUMMARY OF AGE, SEX, AND DIAGNOSIS

OF PATIENTS USED IN THE ORAL AND

INTRAMUSCULAR GLUTATHIONE TRIAL

Control Oral ${ }^{1} \quad$ Intra-

muscular ${ }^{2}$

No. of subjects

Age (years) Range

Sex Mean

Female

Active juvenile cirrhosis

Post-necrotic cirrhosis

Primary biliary cirrhosis

Haemochromatosis

Alcoholic cirrhosis

$1300 \mathrm{mg}$. for 28 days

$2200 \mathrm{mg}$. for 14 days

cirrhosis (2), and haemochromatosis (1). The remaining 10 patients were given two $50 \mathrm{mg}$. glutathione tablets three times daily for 28 days. This group consisted of four males and six females whose mean age was 51 years (38-63 years). The diagnoses, also confirmed by liver biopsy, were: active 'juvenile' (3), post-necrotic (5), and alcoholic cirrhosis (2).

In the second part of the trial, 12 cirrhotic patients were randomly selected. These consisted of four males and eight females of mean age 49 years (34-60 years). The diagnoses, also confirmed by hepatic histology, were: active 'juvenile' (6), post-necrotic (2), primary biliary (1), and alcoholic cirrhosis (3). All 12 patients were given intramuscular glutathione in a dose of $200 \mathrm{mg}$. daily for 14 days. Control patients were not used in this part of the trial since it was felt unjustified to give placebo intramuscular injections.

All of the patients were in a steady state, assessed by body weight and biochemical criteria, during the three months preceding commencement of the trial. Several patients distributed throughout the three groups were receiving long-term diuretics or steroid preparations, but in all cases these had been given for periods of at least three months and were not changed during the trial.

Careful questioning was made concerning any toxic or beneficial effects. Specific questions were also asked with respect to sense of well being, energy, and appetite. Clinical examination included note of skin rashes, cutaneous stigmata of hepatocellular dysfunction, and hepatosplenomegaly. Body weight was recorded on each occasion, as were serum bilirubin, alkaline phosphatase, aspartate transaminase, serum proteins, and electrophoresis. Bromsulphalein retention was assessed in each case by injecting bromsulphalein, $5 \mathrm{mg}$. per kilogram body weight, intravenously, and taking blood samples from a vein in the opposite arm at four, eight, 12, 16, 20, 30, and 45 minutes. Disappearance curves were plotted in each case, and $t_{\frac{1}{2}}$ and the plasma disappearance rate were calculated, as were percentage retention at 30 and 45 minutes by extrapolation to zero time.

\section{RESULTS WITH ORAL GLUTATHIONE}

CONTROL (PLACEBO) GROUP Two of 10 patients in this group felt generally better following the course

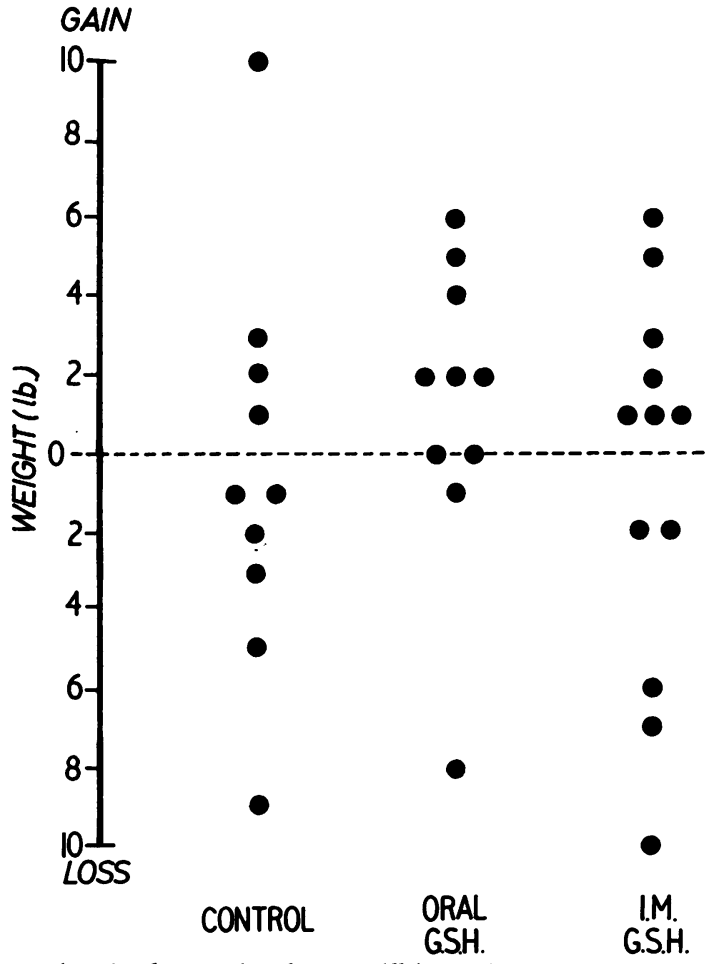

FIG. 1. Body weight changes (lb.) in the controls and in those receiving oral or intramuscular glutathione (GSH).

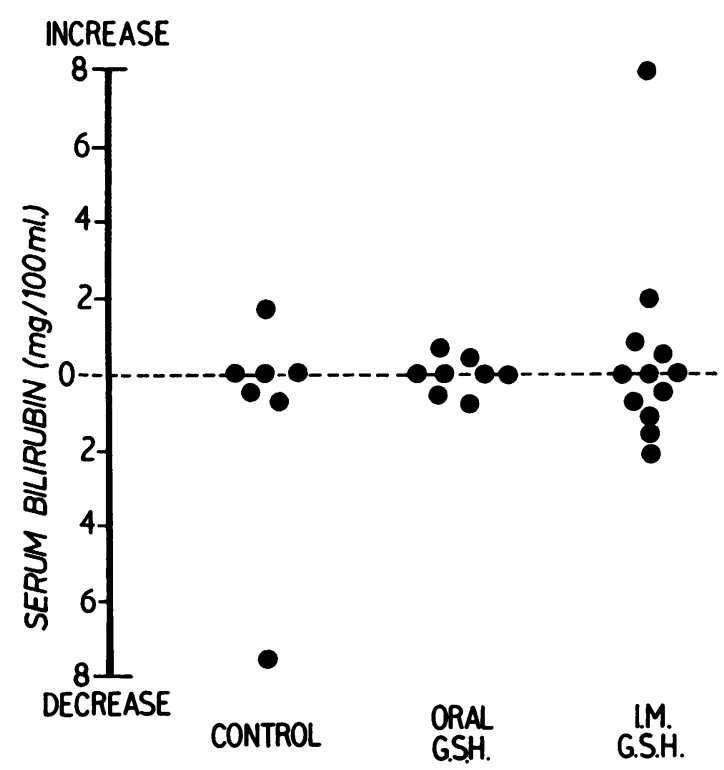

FIG. 2. Changes in serum bilirubin levels ( $\mathrm{mg} .100 \mathrm{ml}$.) in the three groups studied. 


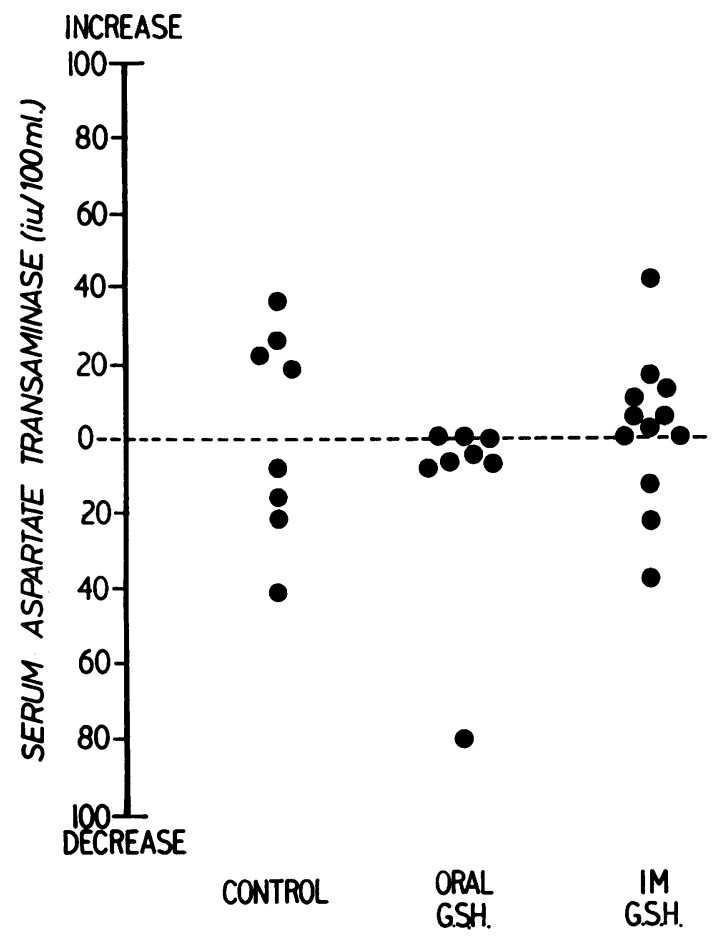

FIG. 3. Changes in serum aspartate transaminase levels (i.u./100 ml.) (normal range 5-17) in the three groups studied.

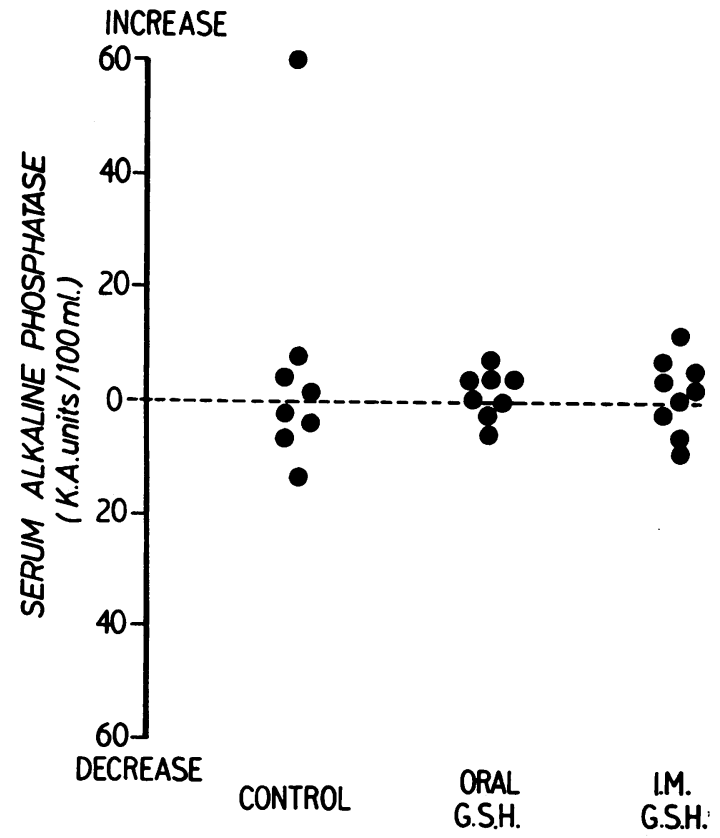

FIG. 4. Changes in serum alkaline phosphatase levels (King-Armstrong units/100 ml.) in the three groups studied. of tablets. Both had increased energy and in one appetite had improved. None complained of any disadvantageous effects while receiving the placebo. Examination revealed a purpuric rash in one individual which was probably related to the cirrhosis. Cutaneous stigmata of liver disease and hepatosplenomegaly did not alter.

Weight changes were usually less than $5 \mathrm{lb}$.; four gained and six lost weight (Fig. 1). Serum bilirubin levels were fairly constant; only in one case was a fall greater than $2 \mathrm{mg} . / 100 \mathrm{ml}$. recorded (Fig. 2). Aspartate transaminase levels fell in four patients, and rose in four (Fig. 3). Alkaline phosphatase levels (Fig. 4) increased in four and decreased in four patients.

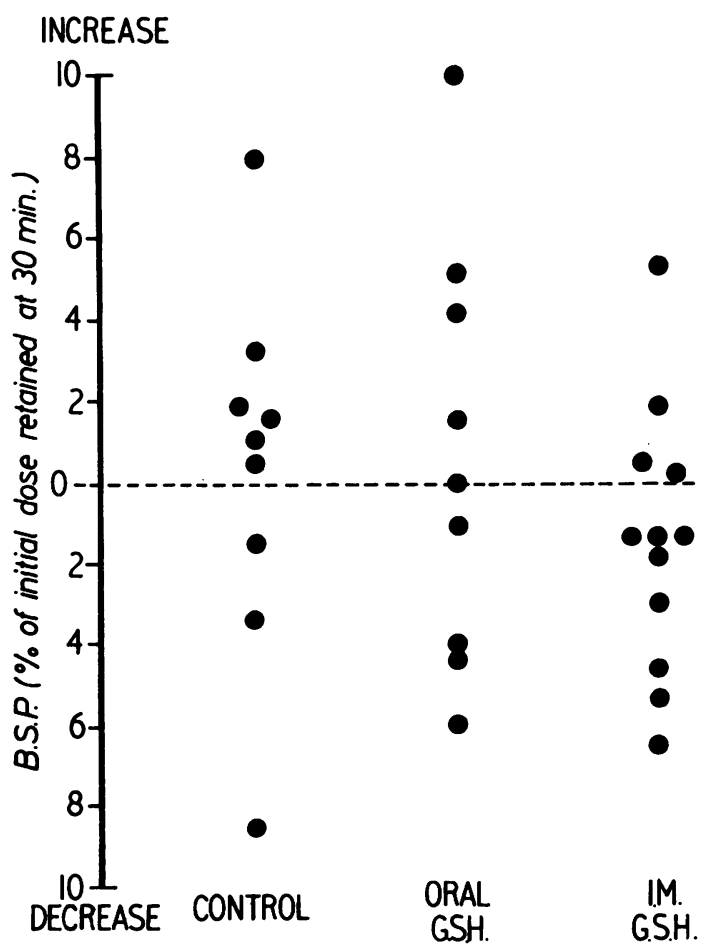

FIG. 5. Changes in bromsulphalein retention at 30 minutes (\% of the initial $5 \mathrm{mg} . / \mathrm{kg}$. dose retained) in the three groups studied.

Serum albumin and globulin levels were recorded in only three patients and showed no significant alteration. Bromsulphalein retention at $30 \mathrm{~min}$. (Fig. 5) and $45 \mathrm{~min}$. showed an improvement in three patients, but a deterioration in a further six cases. Bromsulphalein half time $\left(\mathrm{t} \frac{1}{2}\right)$ showed improvement in three cases, no change in three, and worsening in three patients (Fig. 6). 


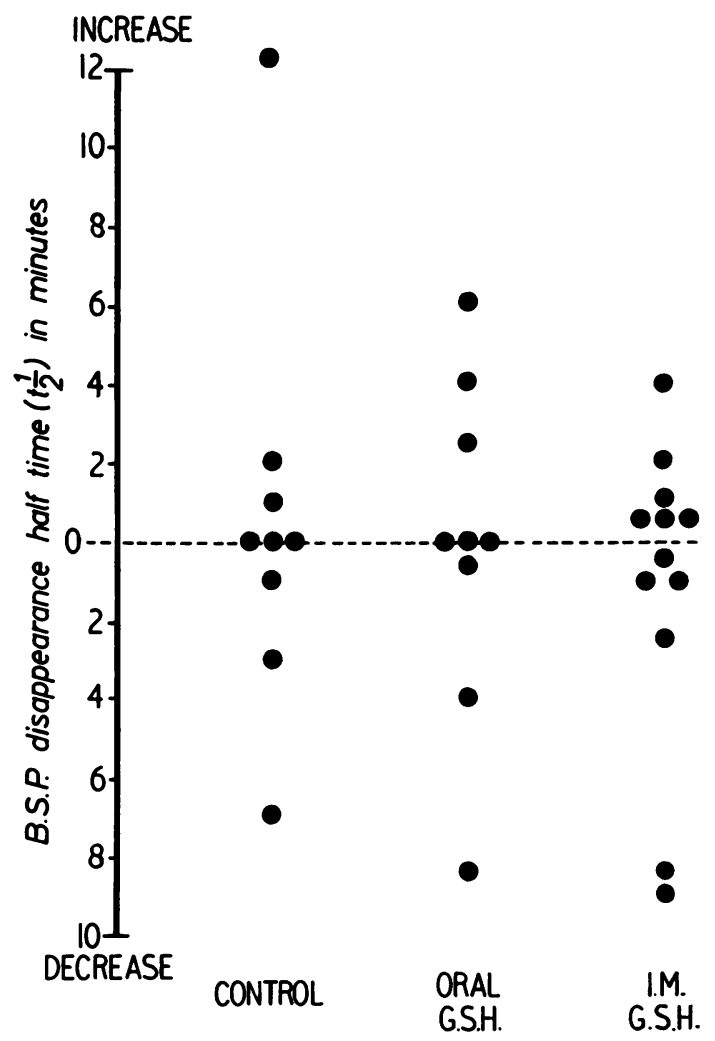

FIG. 6. Changes in the disappearance half-time of bromsulphalein $\left(t \frac{1}{2}\right)$ in minutes, in the three groups studied.

TEST (ORAL GLUTATHIONE) GROUP Four of the 10 patients in this group felt that they had more energy while receiving the tablets, and in two of these appetite had improved. Four patients complained of severe indigestion or 'bloatedness' while taking the tablets, and several noted a feeling of distension in the right hypochondrium. Physical signs were unchanged in all patients.

Weight increased in six patients, in two remained constant, and in two decreased. Serum bilirubin level showed no change in four, a slight rise in two, and a fall in two. Serum aspartate transaminase levels showed no change in three, a slight fall in four, and a moderate fall (80 i.u./100 ml.) in one patient. Serum alkaline phosphatase levels fell in two, remained constant in one, and were raised in five patients. Serum albumin and globulin levels were estimated before and after glutathione in only six patients and showed no significant alteration. Bromsulphalein retention at 30 and 45 minutes showed an improvement in four cases, a worsening in four and remained constant in one. Bromsulphalein disappearance half times remained constant in three, improved in three, and were prolonged in three patients.

RESULTS WITH INTRAMUSCULAR GLUTATHIONE

Five of the 12 patients in this group felt more energetic and able to cope with their occupational activities more adequately, and of these four had a much improved sense of well being. One patient noted a subjective improvement in appetite. Indigestion and excessive thirst in two cases were the only undesirable effects noted. A patient with active 'juvenile' cirrhosis developed a rash characteristic of erythema multiforme; this may well have been related to the liver condition. No other changes were noted on physical examination following the treatment.

Weight increased in seven and fell in five patients. Serum bilirubin levels fell in five, remained constant in three, and rose in four patients. Serum aspartate transaminase levels fell in three, remained constant in two, and showed an elevation in seven cases. Alkaline phosphatase levels were decreased in three, increased in five, and remained constant in one case. The serum albumin level rose in six and fell in three; and the total serum globulin level fell in three and showed a rise in seven cases. Bromsulphalein retention at $30 \mathrm{~min}$. and $45 \mathrm{~min}$. showed an improvement in eight and seven cases respectively, and a worsening in four and five cases. The half time $\left(\mathrm{t} \frac{1}{2}\right)$ of bromsulphalein disappearance improved in six, and became worse in six cases.

\section{DISCUSSION}

On theoretical grounds the glutathione might have been expected to improve hepatic function. This is especially so in respect of conjugation processes such as the metabolism of bromsulphalein. It was therefore disappointing that there was no real difference between controls and test subjects as regards objective criteria such as depth of jaundice, routine biochemical tests of liver function, or the half life of bromsulphalein.

Glutathione has been thought to be an effective hepatic tonic but here again there were no real differences in well being, appetite, or weight gain in the various groups. Perhaps a higher proportion of patients receiving intramuscular glutathione noted subjective improvement than did those receiving the oral tablet or the placebo. The group receiving the intramuscular drug, however, were not properly controlled as it was not thought justifiable to give placebo injections. The beneficial effect of the intramuscular preparation might be related to the psychological value of an injection compared with an oral form of therapy. 
Whether or not glutathione is absorbed from the gastrointestinal tract and if so the form of the absorbed compound has not been investigated. It was this doubt concerning absorption that prompted the second (intramuscular) part of the trial. Chromatographic analysis of samples of the glutathione used in the trial confirmed its identity with other commercially produced preparations of this substance. The drug does not seem to be toxic and the mild digestive disturbance following its oral use was unexplained and not severe.

This work emphasizes the importance of carrying out properly controlled trials of any remedy recommended for the treatment of a chronic disease such as cirrhosis. Had the placebo not been used it might have been possible to attribute to oral glutathione powers of improving liver function. The true state of affairs was obvious when similar results were seen in the controls receiving a placebo.

\section{SUMMARY}

Twenty well-compensated cirrhotic patients, divided into two equal groups by a double-blind technique, received either oral glutathione $(300 \mathrm{mg}$. daily) or placebo tablets for four weeks. No consistent differences were noted in well being, body weight, or serum levels of bilirubin, aspartate transaminase, or alkaline phosphatase. The percentage retention and disappearance of half-time bromsulphalein were not significantly altered.

A further 12 randomly selected cirrhotic patients were given intramuscular glutathione $(200 \mathrm{mg}$. daily) for two weeks. No significant alteration was observed in the biochemical parameters although an improved sense of well being was seen more often in the patients receiving intramuscular glutathione than in the controls and those treated orally. No toxic effects of glutathione were observed.

We wish to thank Dr. Lucien Lakah for his interest in this work; and the Jouillie Laboratories, Paris, both for supplying the glutathione used in the clinical trial and for their financial assistance. We are also grateful for the valuable support given by Dr. M. M. Fisher during the early stages of this investigation.

One of us (G.C.C.) was in receipt of a grant from the
William Shepherd Bequest to the Royal Free Hospital, London.

\section{REFERENCES}

Barnes, M. M., and James, S. P. (1957). Glutathione and formation of mercapturic acid in vivo. Biochem. J., 56, 3P.

Beattie, J., and Marshall, J. (1944). Methionine in the treatment of liver damage. Nature (Lond.), 153, 525-526.

Binet, L., and Wellers, G. (1951). Rôle du glutathion lors de l'intoxication du rat par le monobromobenzène. Bull. Soc. Chim. biol. (Paris), 33, 279-285.

Bloch, K. (1949). The synthesis of glutathione in isolated liver. J. biol. Chem., 179, 1245-1254.

- and Anker, H. S. (1947). Synthesis of glutathione in isolated liver. Ibid., 169, 765-766.

Booth, J., Boyland, E., and Sims, P. (1960). Metabolism of polycylic compounds. 15. The conversion of naphthalene into a derivative of glutathione by rat-liver slices. Biochem. J., 74, 117-122.

Bray, H. G., and Franklin, T. J. (1957). Glutathione and formation of mercapturic acid in vitro. Ibid., 66, 3P.

Brunschwig, A., Johnson, C., and Nichols, S. (1945). Carbon tetrachloride injury of the liver. The protective action of certain compounds. Proc. Soc. exp. Biol. (N.Y.), 60, 388-391.

Christensen, H. N., Rothwell, J. T., Sears, R. A., and Streicher, J. A. (1948). Association between rapid growth and elevated cell concentrations of amino acids. II. In regenerating liver after partial gastrectomy in the rat. J. biol. Chem., 175, 101-105.

De Groote, J., and Vandenbroucke, J. (1956). La glutathionémie chez les hépatiques. Acta gastro-ent. belg., 19, 97-104.

Douglas, G. W., and Mortensen, R. A. (1956). The rate of metabolism of brain and liver glutathione in the rat studied with $\mathrm{C}^{14}$-glycine. J. biol. Chem., 222, 581-585.

Harington, C. R., and Mead, T. H. (1935). Synthesis of glutathione. Biochem. J., 29, 1602-1611.

Helbeig, G. (1954). Verhalten and klinische Bedeutung des SHGlutathion bei verschiedenen Hepatopathien. 1. Klinischer Teil. Z. Kinderheilk., 74, 622-634.

Isherwood, F. A. (1959). Chemistry and biochemistry of glutathione. Biochem. Soc. Symp., 17, 3-16.

Javitt, N. B. (1961). Glutathione: role in conjugation in the liver. Amer. J. Med., 30, 341-344.

- Wheeler, H. O., Baker, K. J., Ramos, O. L., and Bradley, S. E. (1960). The intrahepatic conjugation of sulfobromophthalein and glutathione in the dog. J. clin. Invest., 39, 1570-1577.

Jocelyn, P. C. (1958). The importance of thiol compounds in the causation of disease. Clin. chim. Acta, 3, 401-418.

Johnston, R. B., and Bloch, K. (1951). Enzymatic synthesis of glutathione. J. biol. Chem., 188, 221-240.

Lindan, O., and Work, E. (1953). Experimental liver necrosis in rats. Biochem. J., 55, 554-566.

Peters, R. A., Thompson, R. H. S., King, A. J., Williams, D. I., and Nicol, C. S. (1944). Sulphur-containing amino-acids and jaundice. Nature (Lond.), 153, 773.

Read, A. E., Sherlock, S., and Harrison, C. V. (1963). Active 'juvenile' cirrhosis considered as part of a systemic disease and the effect of corticosteroid therapy. Gut, 4, 378-393.

Waelsch, H. (1952). Certain aspects of intermediary metabolism of glutamine, asparagine, and glutathione. Advanc. Enzymol., 13, 237-319.

_ and Rittenberg, D. (1941). Glutathione. I. The metabolism of glutathione studied with isotopic glycine. J. biol. Chem., 139, 761-774.

Wieland, T. (1954). In Glutathione. Proceedings of a Symposium held at Ridgefield, Connecticut, pp. 45-57. Academic Press, New York. 